\title{
Functional Outcome After Primary Decompressive Craniectomy for Acute Subdural Hematoma in Severe Traumatic Brain Injury
}

\author{
Safwat ABOUHASHEM ${ }^{1,2,3}$, Hany ELDAWOODY ${ }^{2,4,5}$ \\ 'Zagazig University, Faculty of Medicine, Department of Neurosurgery, Egypt \\ ${ }^{2}$ Kingdom Hospital, Riyadh, Saudi Arabia \\ ${ }^{3}$ Saudi German Hospital, Department of Neurosurgery, Riyadh, Saudi Arabia \\ ${ }^{4}$ Mansoura University Hospital, Department of Neurosurgery, Mansoura, Egypt \\ ${ }^{5}$ Prince Mohamed Bin Abdul-Aziz Hospital Riyadh, Saudi Arabia \\ Corresponding author: Hany ELDAWOODY hanyeldawaoody@yahoo.com
}

\section{ABSTRACT}

AIM: To evaluate the impact of primary decompressive craniectomy (DC) on the functional outcome in patients with post traumatic acute subdural hematoma (SDH).

MATERIAL and METHODS: A retrospective cohort analysis of 92 patients with post traumatic acute SDH who underwent primary DC and evacuation of SDH. The primary outcome variable is Glasgow outcome scale at 6 months follow up, while exposure variables are demographic data (age and gender), initial Glasgow coma scale, Marshall Classification Score of traumatic brain injury, midline shift, side of the lesion, surgery related complications and time of cranioplasty.

RESULTS: Out of the 92 patients in this study, 89.1\% were males and the mean age was $30.2 \pm 14.4$ years. At admission, the mean Glasgow Coma Scale (GCS) was $5.8 \pm 2$ and mean Marshall score was $4.7 \pm 0.7$, while the average midline shift was $8.8 \pm$ $3.5 \mathrm{~mm}$. Right decompressive craniectomy was performed in $46(50 \%)$ patients, while in $2(2.1 \%)$ cases, bi-frontal craniectomy was performed and left decompressive craniectomy was performed in $44(47.8 \%)$ patients. Mortality was reported in 38 patients $(41.3 \%)$ and poor outcome was reported in 24 patients $(26.1 \%)$, while 30 patients (32.6\%) showed good outcome. During the follow up period, cranioplasty for restoration of the bone defect was completed in 52 patients.

CONCLUSION: Primary decompressive craniectomy after STBI for post-traumatic acute subdural hematoma improved the favorable outcome whenever the initial GCS $>4$ among adult patients.

KEYWORDS: Acute SDH, Decompressive Craniectomy, Outcome

ABBREVIATIONS: DC: Decompressive craniectomy, TBI: Traumatic brain injury, STBI: Severe traumatic brain injury, ASDH: Acute subdural hematoma, GCS: Glasgow coma scale, SDH: Subdural hematoma, CT: Computed tomography, GOS: Glasgow outcome scale

\section{INTRODUCTION}

A cute Post traumatic subdural hematoma (SDH) increases the major morbidity and mortality in patients with severe traumatic brain injury (STBI) $(30,39,51)$.
Surgical evacuation is the mainstay of treatment in patients with mass effect; furthermore, the control of the post traumatic intracranial hypertension may out weight the importance of hematoma evacuation per se $(25,51)$. 
For a long time, craniotomy and hematoma evacuation has been the main surgical procedure of posttraumatic acute SDH; furthermore, decompressive craniectomy (DC) may be an alternative surgical procedure which in addition to hematoma evacuation, provides an extra space to accommodate the edematous brain tissue and controls the post traumatic intracranial hypertension (39).

One third of patients after the initial craniotomy and evacuation of acute SDH ultimately needs secondary DC (8), so early planned aggressive intervention in the form of primary DC, evacuation of the hematoma and duroplasty would prevent secondary brain insult $(46,50,53)$; however, there is no universal consensus regarding the appropriate surgical strategy and the decision to perform either craniotomy or primary DC which remains a controversial issue till date $(36,39,53)$.

In this study, the outcome of patients who underwent primary DC and evacuation of acute SDH after severe traumatic brain injury was retrospectively evaluated to clarify the effect of primary DC on the functional status after severe traumatic brain injury associated with acute SDH. The aim of this study is to evaluate the impact of primary DC on the functional status in patients who presented with severe traumatic brain injury and post traumatic acute SDH.

\section{MATERIAL and METHODS}

All procedures performed in studies involving human participants were in accordance with the ethical standards of the institutional and/or national research committee [Kingdom Hospital ethical committee (NS 17-07-2018) on July 2018] and with the 1964 Helsinki Declaration and its later amendments or comparable ethical standards.

This is a retrospective collaborative cohort analysis of 92 patients with severe TBI (Glasgow Coma Scale score $\leq 8$ ) with acute SDH and mass effect who underwent primary DC and evacuation of the hematoma between 2013 and 2019. The primary outcome variable is Glasgow outcome scale (GOS) (21), while exposure variables are demographic data (age and gender), initial Glasgow coma scale, Marshall Classification Score of traumatic brain injury, midline shift, side of the lesion, surgery related complications and time of cranioplasty.
Over the past decade in our institutions, primary decompressive craniectomy and hematoma evacuation for post traumatic acute SDH was generally agreed on being the main line of surgical management in such patients. The end point of the study was death, or 6 months follow up.

Patients with Glasgow Coma Scale $>8$, patients with isolated extradural hematoma, patients with previous neurological deficit, patients with GCS-3 and bilaterally dilated non-reactive and those with incomplete data were excluded.

The Glasgow Coma Scale $(47,48)$ (Table I) was used to classify the initial neurological status while Marshall Classification Score of traumatic brain injury (31) was used to classify the radiological findings (Table II).

The six degrees initial neurological condition of the patients' GCS (GCS 3-8) were further subdivided into three subgroups; critically severe (GCS 3-4), critically moderate (GCS 5-6) and critically mild (GCS 7-8).

In this study, the extra-axial fluid collection was reported as a complication only being significant whenever its thickness was more than $1 \mathrm{~cm}$, whether the content was blood, serosanguinous, infected fluid, or mere CSF collection.

The outcome was categorized according to Glasgow Outcome Scale (21) (Table III) into good outcome (GOS 4-5), poor outcome (GOS 2-3) and death (GOS 1), then the functional status was dichotomized into unfavorable outcome (GOS 1-3) versus favorable outcome (GOS 4-5).

\section{Statistical Analysis}

A statistical analysis was carried out using Stata Software version 15.1. Descriptive statistical data were summarized as mean $\pm \mathrm{SD}$ and/or proportions as appropriate. We compared the mean, or proportion of the exposure factors between patients with favorable outcome and patients with unfavorable outcome using t-test, univariate logistic regression test, chisquare test, Fisher exact test and Kruskal-Wallis equality-ofpopulations rank test.

Stratification and a multivariable logistic regression were performed to eliminate the effects of confounders and to identify the independent clinical factors associated with unfavorable outcome and the final multivariable model included all variables with $\mathrm{p}$-value $<0.05$.

Table I: Glasgow Coma Score (Score of 13 or Higher Correlates with a Mild Brain Injury, 9 to 12 is a Moderate Injury and 8 or Less a Severe Brain Injury).

\begin{tabular}{cccc}
\hline & Best Eye Response & Best Verbal Response & Best Motor Response \\
\hline $\mathbf{1}$ & No eye opening & No verbal response & No motor response \\
\hline $\mathbf{2}$ & Eye opening to pain & Incomprehensible sounds & Extension to pain \\
\hline $\mathbf{3}$ & Eye opening to verbal command & Inappropriate words & Flexion to pain \\
\hline $\mathbf{4}$ & Eyes open spontaneously & Confused & Withdrawal from pain \\
\hline $\mathbf{5}$ & & Orientated & Localizing pain \\
\hline $\mathbf{6}$ & & & Obeys Commands \\
\hline
\end{tabular}


Table II: Marshall CT Scale of Traumatic Brain Injury

\begin{tabular}{ll}
\hline Scale & CT findings \\
\hline Category I & $\begin{array}{l}\text { midline shift of } 0 \text { to } 5 \mathrm{~mm} \\
\text { basal cisterns remain visible } \\
\text { no high or mixed density lesions }>25 \mathrm{~cm}^{3}\end{array}$ \\
\hline Category II & $\begin{array}{l}\text { midline shift of } 0 \text { to } 5 \mathrm{~mm} \\
\text { basal cisterns compressed or completely effaced } \\
\text { no high or mixed density lesions }>25 \mathrm{~cm}^{3}\end{array}$ \\
\hline Category III & $\begin{array}{l}\text { midline shift of } 0 \text { to } 5 \text { mm } \\
\text { basal cisterns compressed or completely effaced } \\
\text { no high or mixed density lesions }>25 \mathrm{~cm}^{3}\end{array}$ \\
\hline Category IV & $\begin{array}{l}\text { midline shift }>5 \text { mm } \\
\text { no high or mixed density lesions }>25 \mathrm{~cm}^{3}\end{array}$ \\
\hline Category V & any lesion evacuated surgically \\
\hline Category VI & $\begin{array}{l}\text { high or mixed density lesions }>25 \mathrm{~cm}^{3} \\
\text { not surgically evacuated }\end{array}$ \\
\hline
\end{tabular}

Table III: Glasgow Outcome Scale

\begin{tabular}{ll}
\hline Scale & Description \\
\hline GOS-1 & Death \\
\hline GOS-2 & Persistent vegetative state: Minimal responsiveness \\
\hline GOS-3 & Severe disability: Conscious but disabled; dependent on others for daily support \\
\hline GOS-4 & Moderate disability: Disabled but independent; can work in sheltered setting \\
\hline GOS-5 & Good recovery: Resumption of normal life despite minor deficits \\
\hline
\end{tabular}

Table IV: Characteristics of the Study Population

\begin{tabular}{lc}
\hline \multicolumn{1}{l}{$\begin{array}{l}\text { Variables } \\
\text { Number of patients }\end{array}$} & Number (\%) Mean \pm SD \\
\hline Age & $30.2 \pm 14.4$ \\
\hline Pediatric & $4(4.35 \%)$ \\
\hline Adult & $84(91.3 \%)$ \\
\hline Elderly & $4(4.35 \%)$ \\
\hline Gender & \\
\hline Female & $82(89.1 \%)$ \\
\hline GCS & $10(10.9 \%)$ \\
\hline Marshal scale & $5.8 \pm 2$ \\
\hline Midline shift & $4.7 \pm 0.7$ \\
\hline Right side lesion & $8.8 \pm 3.5$ \\
\hline
\end{tabular}

\section{RESULTS}

Out of the 92 patients in this study, $89.1 \%$ were males and their mean age was $30.2 \pm 14.4$ years, 4 patients $(4.4 \%)$ were younger than 16 years and 4 patients $(4.4 \%)$ were older than 65 years. At admission, the mean Glasgow Coma Scale (GCS) was $5.8 \pm 2$ and mean Marshall score was $4.7 \pm 0.7$, while the average midline shift was $8.8 \pm 3.5$ and left sided decompressive craniectomy was done for 44 patients (47.8\%). During the follow up period, cranioplasty for restoration of the bone defect was completed in 52 patients (Table IV).

At the end point of the study, mortality was reported in 38 patients $(41.3 \%)$ and poor outcome was reported in 24 patients $(26.1 \%)$, while 30 patients $(32.6 \%)$ showed good outcome (Table V). The surgery related complications (Table V) included significant postoperative collections in 18 patients $(19.6 \%)$, CSF leak in 6 patients $(6.5 \%)$, infection in 6 patients $(6.5 \%)$, sunken flap in 8 patients $(8.7 \%)$ and hydrocephalus in 10 patients (10.9\%). The base line criteria of the study population are summarized in Table IV.

Correlation between GOS and initial GCS was detected by linear regression analysis (Figure 1), and the regression coefficient was found to be 0.4 . 
Table V: Surgery Related Complications and Outcome

\begin{tabular}{cc}
\hline Variable & $\begin{array}{c}\text { Number (\%) } \\
\text { Mean } \pm \text { SD }\end{array}$ \\
\hline Surgery related complications & $18(19.6 \%)$ \\
\hline Post-operative extra-axial collection & $6(6.5 \%)$ \\
\hline Post-operative infection & $6(6.5 \%)$ \\
\hline Post-operative CSF leak & $8(8.7 \%)$ \\
\hline Sunken flap & $10(10.9 \%)$ \\
\hline HoS & $2.6 \pm 1.6$ \\
\hline Morocephalus & $38(41.3 \%)$ \\
\hline Poor functional status & $24(26.1 \%)$ \\
\hline Good functional status & $30(32.6 \%)$ \\
\hline Functional outcome status & \\
\hline Favorable outcome & $30(32.6 \%)$ \\
\hline Unfavorable outcome & $62(67.4 \%)$ \\
\hline
\end{tabular}

After dichotomizing the patients into favorable outcome (GOS 4-5) and unfavorable outcome (GOS 1-3), the exposure variables were compared and revealed that the initial GCS was lower in patients with unfavorable outcome with statistically significant value $(\mathrm{p}<0.0001-$ Table V).

After stratification of GCS subgroups, all patients with critically severe initial neurological status (GCS 3-4) showed unfavorable outcome, while the likelihood of favorable outcome in patients with critically moderate initial neurological status (GCS 5-6) was $30 \%$ and in patients with critically mild initial neurological status (GCS 7-8), the likelihood of favorable outcome was $57.1 \%(p<0.0001$ - Table VI, Figure 2).

Moreover, when statistical analysis was performed between critically moderate and critically mild initial neurological status groups, there was statistically significant difference in GOS $(p=0.046$ - Table VI).

Although there were no statistically significant differences in demographic data between both groups [Table 6], after stratification of the data, unfavorable outcome could be predicted in elderly patients > 65 years, also favorable outcome could be predicted in pediatric patients $<16$ years with statistically significant difference $(p$ value $=0.049$ - Table VI, Figure 3).

Despite the tendency of lower mean time for cranioplasty after DC among favorable outcome group compared to that of unfavorable outcome patients' group, there was no statistically significant difference $(61.9$ and 85.2 days, respectively, $\mathrm{p}=0.058$ - Table V, Figure 4).

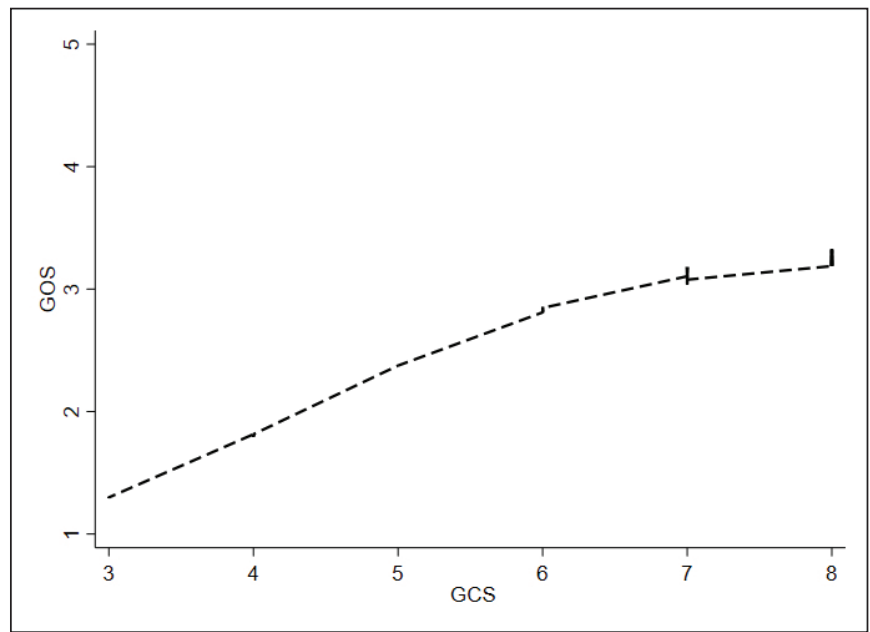

Figure 1: Correlation between GOS and initial GCS.

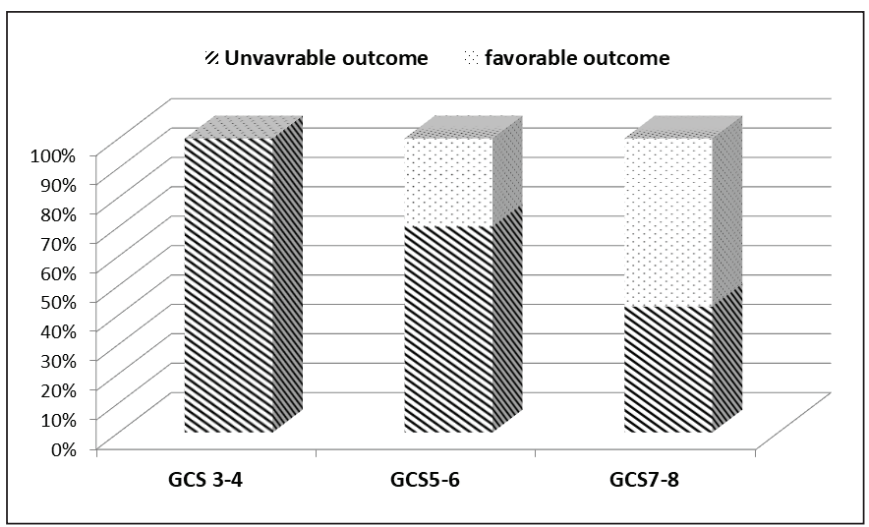

Figure 2: Favorable and unfavorable outcome according to the severity of initial neurological status.

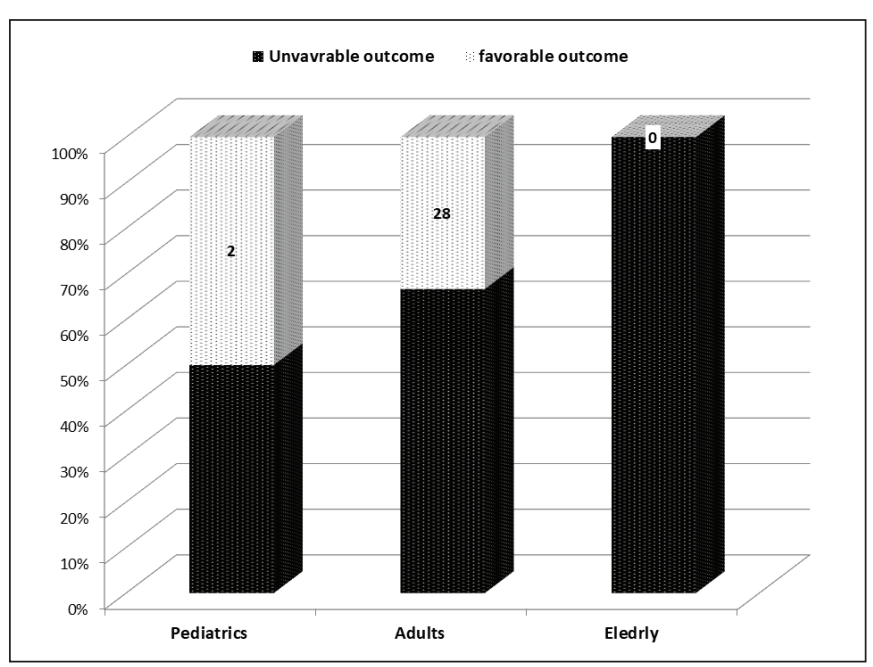

Figure 3: Favorable and unfavorable outcome according to the Age group. 
Table VI: Comparison of Demographics and Baseline Clinical Characteristics Between Patients with Favorable and Patients with Unfavorable Outcome

\begin{tabular}{|c|c|c|c|}
\hline & $\begin{array}{c}\text { Favorable outcome } \\
30(32.6 \%) \\
\end{array}$ & $\begin{array}{c}\text { Unfavorable outcome } \\
62(67.4 \%) \\
\end{array}$ & $\mathbf{p}$ \\
\hline Gos & $4.7 \pm 0.5$ & $1.6 \pm 0.8$ & $<0.0001^{\star \star \star}$ \\
\hline $\operatorname{Age}(Y)$ & $31.1 \pm 12$ & $35.8 \pm 18$ & 0.2 \\
\hline Pediatric (Less than 16y) & $2(50 \%)$ & $2(50 \%)$ & \\
\hline Adult (16-65) & $28(35 \%)$ & $52(65 \%)$ & $0.049^{*}$ \\
\hline Elderly (More than 65y) & $0(0 \%)$ & $8(100 \%)$ & \\
\hline \multicolumn{4}{|l|}{ Gender } \\
\hline Male & $28(34.1 \%)$ & $54(65.8 \%)$ & \multirow{2}{*}{0.36} \\
\hline Female & $2(20 \%)$ & $8(80 \%)$ & \\
\hline \multicolumn{4}{|c|}{ Baseline clinical and radiological findings } \\
\hline Mean GCS & $7.3 \pm 0.9$ & $5.1 \pm 2$ & $<0.0001^{\star \star \star}$ \\
\hline \multicolumn{4}{|l|}{ GCS subgroups } \\
\hline Critically severe (GCS 3-4) & $0(0 \%)$ & $30(100 \%)$ & \\
\hline Critically moderate (GCS 5-6) & $6(30 \%)$ & $14(70 \%)$ & \multirow{2}{*}{$<0.046^{\star} \quad<0.0001^{\star \star \star}$} \\
\hline Critically mild (GCS 7-8) & $24(57.1 \%)$ & $18(42.9 \%)$ & \\
\hline Marshall scale & $4.6 \pm 0.6$ & $4.7 \pm 0.8$ & 0.28 \\
\hline Midline shift(mm) & $8.4 \pm 3.2$ & $9 \pm 3.7$ & 0.6 \\
\hline \multicolumn{4}{|l|}{ Side of decompression } \\
\hline Right side decompression & $16(34.8 \%)$ & $30(65.2 \%)$ & \multirow{3}{*}{0.8} \\
\hline left side decompression & $14(31.8 \%)$ & $30(68.2 \%)$ & \\
\hline Bifrontal decompression & $2(100 \%)$ & 0 & \\
\hline Time of Cranioplasty (days) & $61.9 \pm 7.5$ & $85.2 \pm 9.1$ & 0.058 \\
\hline \multicolumn{4}{|l|}{ Complications } \\
\hline Extra-axial collection & $8(26.7 \%)$ & $10(16.1 \%)$ & 0.2 \\
\hline Hydrocephalus & $2(20 \%)$ & $8(80 \%)$ & 0.36 \\
\hline CSF Leak & $2(33.3 \%)$ & $4(66.7 \%)$ & 0.9 \\
\hline Sunken flap & $2(25 \%)$ & $6(75 \%)$ & 0.6 \\
\hline Infection & $4(66.7 \%)$ & $2(33.3 \%)$ & 0.7 \\
\hline
\end{tabular}

Surgery related complications; Marshall radiological scale and midline shift did not show significant difference between patients with favorable and unfavorable outcome (Table VI).

\section{DISCUSSION}

Evacuation of the post-traumatic acute SDH is the main stay of management in patients with severe traumatic brain injury, but the ability to control ICP could be more important than removal of the subdural blood clot (51). Although DC can reduce the intracranial hypertension $(15,25)$, its impact on the clinical outcome is still unclear and is a debatable issue $(20,41,45,53)$. Controversy and debate resides in whether DC after STBI would be able to improve the clinical outcome $(5,6)$ or just decrease the mortality with subsequent severe disability in return $(14,18)$.

The functional outcome after severe traumatic brain injury is a multifactorial issue (43). Although initial neurological status, radiological findings, gender, age, and associated injuries have been studied with conflicting results $(22,33,43)$, there is a wide agreement that post traumatic intracranial hypertension is associated with unfavorable outcome $(22,25,33)$. 


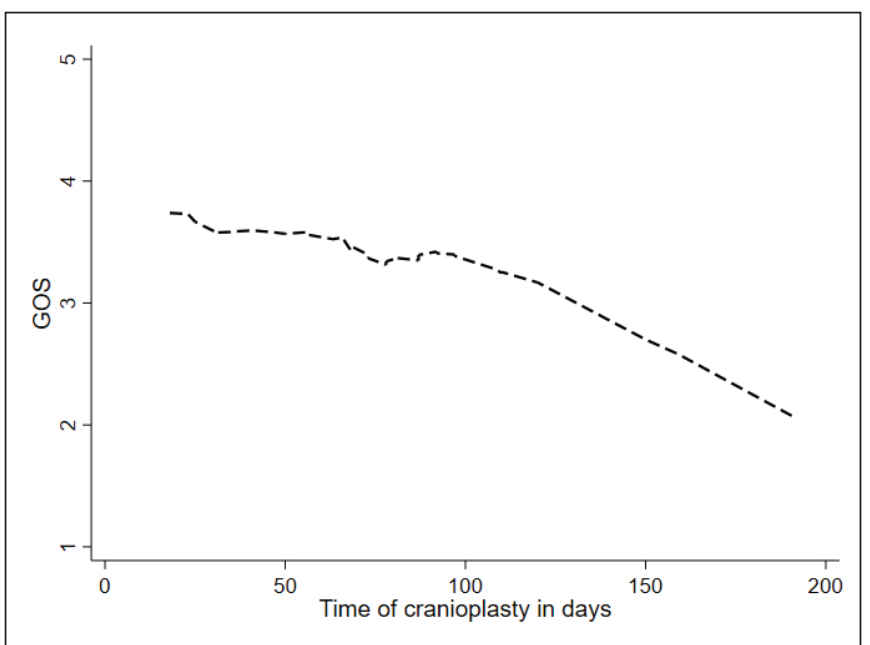

Figure 4: Correlation between time of cranioplasty and GOS.

Decompressive craniectomy could reduce the intracranial hypertension after severe traumatic brain injury (15). In patients associated with acute SDH, decompressive craniectomy could be performed as a pre-planned primary procedure, intraoperative decision in case with fulminant intra-operative swelling or might be secondary after evacuation of the hematoma with post-operative persistent intracranial hypertension $(26,42,52,53)$.

In the randomized study of Hutchinson et al. (20), DC decreased the mortality from $48.9 \%$ at 6 months in patients who were treated non-surgically to $26.9 \%$, while favorable functional status was reported in $27.4 \%$ after DC versus $26.6 \%$ in non-surgical patients.

In the current study, the favorable functional neurological outcome was detected in $32.6 \%$, which is comparable to Hutchinson et al. (20) study. Although the mortality in the current study was reported in $41.3 \%$ of the patients which is higher than the mortality in the Hutchison et al. (20) study, the overall unfavorable outcome which included both mortality and severe disability is generally comparable (in the current study $67.4 \%$ [ $41.3 \%$ and $26.1 \%$, respectively] versus $72.6 \%$ [26.9\% and $45.7 \%$, respectively]).

The higher proportion of mortality rate in the current study could be attributed to the known higher risk of mortality $(30,51)$ due to the presence of acute subdural hematoma in all our TBI cases which was not present mostly in Hutchinson's cases.

In the meta-analysis of Phan et al., poor outcome and mortality were lower in patient with severe traumatic brain injury and subdural hematoma who were treated by craniotomy and evacuation of the hematoma than those who underwent decompressive craniectomy as the poor outcome was $(50.1 \%$ vs. $60.1 \%)$ and the mortality rate was (13.9\% vs. $40.5 \%)$, respectively (39). This can be well explained by the higher proportion of DC over craniotomy for treating TBI cases who presented with poor initial neurological status GCS scale $<8$ (39). However, in the current study, all patients presented with poor neurological status.
Also in the multicenter study of Leitgeb et al., their outcome is comparable to the result of the current study as unfavorable outcome was reported after acute SDH in 65.3\% (46.7\%, $18.6 \%$ mortality and poor functional status, respectively), while $32.2 \%$ showed favorable outcome, and the outcome was unknown in $2.5 \%$ with significantly higher mortality in the non-operative treatment (30).

Initial neurological status has significant correlation with outcome after severe traumatic brain injury $(7,49)$. Glasgow Coma Scale (GCS) is the standardized scale for measurement of neurological status after TBI $(47,48)$. Kodliwadmath et al (24) concluded that GCS can predict the risk and prognosis in patients with traumatic brain injury and significant correlation with outcome after TBI had been reported $(7,35,49)$. Moreover, low GCS $\leq 8$ on admission have poor prognosis and usually correlates with poor outcome either mortality or vegetative state $(11,35)$.

In this study, significant correlation between initial neurological status using GCS scale and functional neurological outcome have been detected (correlation coefficient was 0.4 with $\mathrm{p}$-value $<0.0001$, Figure 1). Moreover, the mean GCS was significantly lower in patients with unfavorable outcome than patients with favorable outcome with $p$-value $<0.0001$ and also after stratification of GCS subgroups, all patients with critically severe initial neurological status (GCS 3-4) showed unfavorable outcome (Figure 2) which is comparable to the study of Bagheri et al (2) where most of their patients who presented with GCS $<5$ showed unfavorable outcome (83\%). Nevertheless, Demetriades et al. (11) reported an overall mortality of $60 \%$ among critically low GCS on admission; on the other hand, there were case reports describing the presence of good functional recovery after decompressive craniectomy for critically severe initial neurological status (GCS 3-4) (1) which was not encountered in the current study.

Although DC in adults has successfully decreased intracranial pressure and decreased mortality, it was associated with more vegetative and poor functional status $(9,16,20)$. However, elderly patients are usually associated with poor outcome after TBI (19). In a retrospective study of surgical outcomes after acute SDH in elderly patients, mortality was reported in $42 \%$ and severe disability in $33 \%$ of the patients while only $24 \%$ had the ability to leave the hospital to nursing care special facility and it was found that there is an increased risk of death after DC in elderly patients over 80 years old, GCS $\leq 8$, or cerebral edema (35). Moreover, in the current study, with small number of elderly cases (only 4 cases) included, all of them showed unfavorable outcome, while better outcome was observed in pediatric patients less than 16 years (Figure 3). Nevertheless, this observation regarding both pediatric and elderly patient groups could not be generalized owing to the small number of each group that needs further research work.

Great discrepancy in the literature regarding the effect of gender on the outcome after TBI, as a poorer outcome in women with TBI than men have been reported $(3,27)$, but no differences between males and females in either acute complications or outcome after TBI were also reported $(37,40)$. In our study, the observed liability of unfavorable outcome among female 

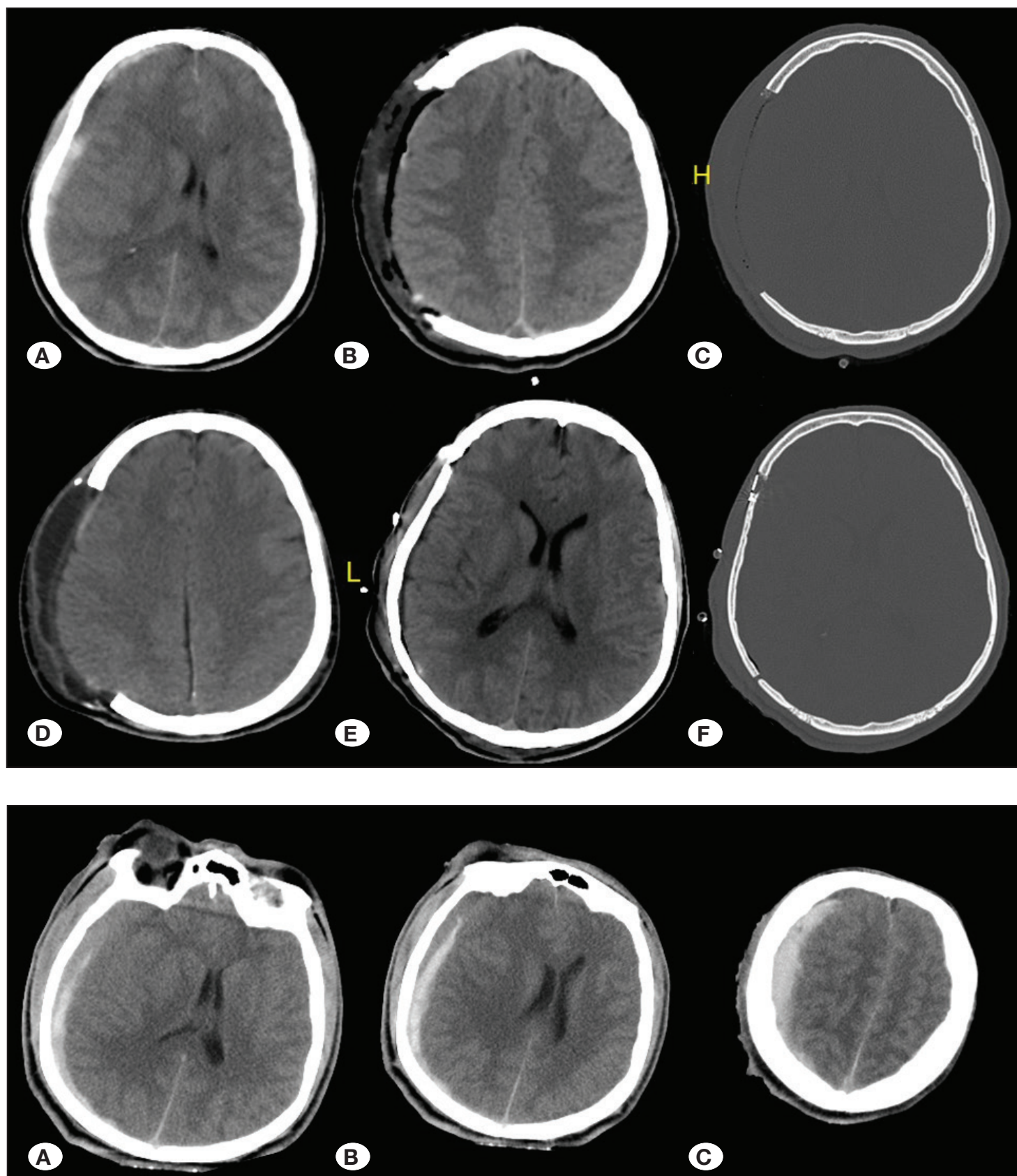

B

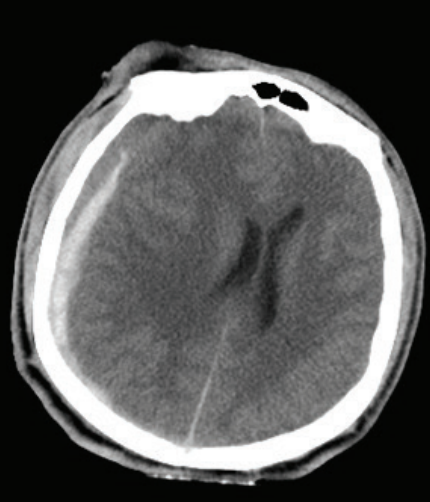

(
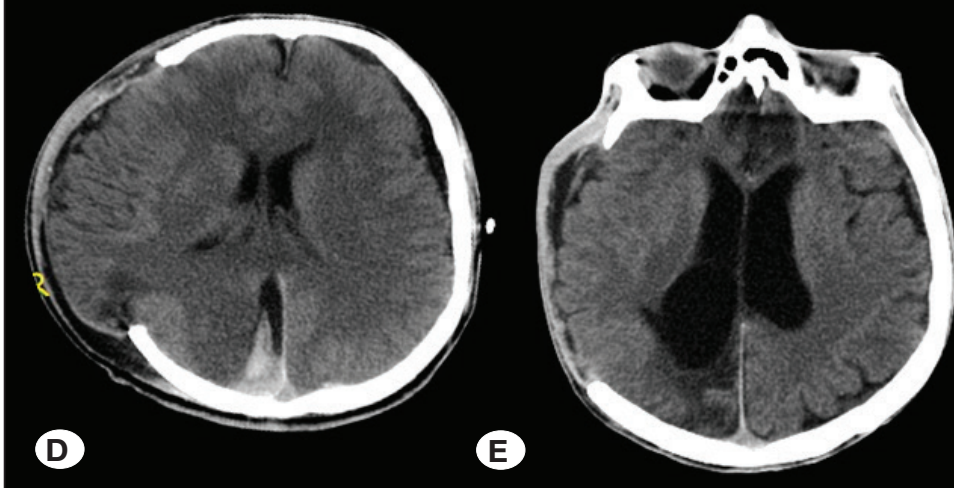

Figure 5: Case

presentation with favorable outcome. A) Initial CT brain shows acute SDH with midline shift 1 cm. B, C) Follow up CT brain shows the early postoperative findings. D) Follow up CT brain after one week. E, F) postcranioplasty follow up CT brain.
Figure 6: Case presentation with unfavorable outcome $\mathbf{A}, \mathbf{B}, \mathbf{C})$ Initial CT brain shows acute $\mathrm{SDH}$ with midline shift more than $1 \mathrm{~cm}$ D) Follow up CT brain shows the early postoperative findings.

E) Delayed follow up CT brain immediately before Cranioplasty F) post-cranioplasty follow up CT brain. 
patients could not be relied on, owing to the small number of female patients included in this study (11\%, 10 patients).

Different radiological scales were used to assess the severity of $\mathrm{TBI}$ as the initial radiological evaluation can predict outcome in patients with TBI $(34,38)$. Marshal CT score (14) was used as radiological predictors for the outcome after TBI and higher score was found to be significantly associated with early mortality (23). In this study, there was no initial radiological significant difference between patients with favorable and unfavorable outcome as all patients in this study had subdural hematoma which made them to have nearly similar Marshall score (Table VI).

The midline shift in the initial CT scan of the brain may indicate the severity of mass effect and liability for herniation. In this study, the degree of midline shift in the preoperative imaging between patients with favorable and patients with unfavorable outcome was compared and showed no significant difference between both patient groups.

Functionally significant Brodmann's areas such as Broca's area and Wernicke's area are found in the dominant hemisphere which is usually on the left side, so left sided lesions may have worse outcome than right sided lesion; but in this study, there was no difference in the functional outcome between right and left side DC (Table VI).

Complications after DC involve blooming of contusions, contralateral acute subdural hematoma, infection, sunken flap and hydrocephalus (32). In our study, the most common complications were extra-axial collections, infection, hydrocephalus and sunken flap, but there was no significant difference in the post-operative complications (Table VI) between patients with favorable and patients with unfavorable outcome.

The reported frequency of extra-axial fluid collection is as high as $25-60 \%$ (32), while in our study, it was reported in 18 patients (19.6\%). The extra-axial fluid collection after DC could be attributed to alteration in CSF dynamics together with increase in the cerebral perfusion pressure after removal of the bone flap $(29,54)$. Hydrocephalus after DC for TBI has been reported to range from $10 \%$ to $40 \%$ (32), while in our study, the incidence of hydrocephalus was reported in $11 \%$ without observed influence on the functional outcome. Sunken flap is a delayed underreported complication after DC in the literature, although it has been reported in $10 \%$ of DC cases by Kurland et al (28). In the current study, it was reported in 8 patients $(8.5 \%)$. Sunken flap was observed whenever cranioplasty has been delayed and could be attributed to unopposed flap compression by the atmospheric pressure especially after subsidence of raised ICP (13). Post-operative infection has been reported in $1-10 \%$ of patients after DC $(17,44)$. In the current study, infection was encountered in 6 patients $(6.5 \%)$, which is comparable to other literatures. Several factors could influence the infection rate such as large scalp incision; small based flap pedicle that might lead to wound breakdown and secondary infection $(32,44)$.

Restoration of the skull bone after DC improves the hemodynamics of the brain and CSF flow, facilitates the rehabilitation and enhances the physical and cognitive recovery $(4,10,12)$ but the timing of cranioplasty is still a controversial issue and in this study, there is a tendency for better outcome with earlier restoration of skull bone defect (Figure 4), yet it is still statistically insignificant (correlation coefficient is 0.007 and $p$ value is 0.1 ).

Despite the presence of several studies in the literature discussing the value of DC, the current study to the best of our knowledge, involved only patients with severe traumatic brain injury (GCS 3-8), while most of other research studies were dealing with $\mathrm{TBI}$ in general; which might lead to pooling of results between mild, moderate and severe TBI patients. In addition, the current study has discussed almost all the important clinical and radiological factors that might affect the functional outcome among severe TBI patients in particular which were not frequently addressed in other previous studies. Nevertheless, in the current study, severe TBI patients (GCS $\leq 8$ ) have been further subdivided into three subgroups; critically severe (GCS $3-4$ ), critically moderate (GCS 5-6), and critically mild (GCS 7-8).

\section{CONCLUSION}

Primary decompressive craniectomy after STBI for posttraumatic acute subdural hematoma improved the favorable outcome whenever the initial GCS >4 among adult patients.

\section{AUTHORSHIP CONTRIBUTION}

\section{Study conception and design: SA \\ Data collection: SA, HE}

Analysis and interpretation of results: $S A$

Draft manuscript preparation: SA, HE

Critical revision of the article: $\mathrm{HE}$

All authors (SA, HE) reviewed the results and approved the final version of the manuscript.

\section{REFERENCES}

1. Afif A: Decompressive craniectomy following severe traumatic brain injury with an initial glasgow coma scale score of 3 or 4 . Clin Surg 4: 2503, 2019

2. Bagheri SR, Alimohammadi E, Saeedi H, Sepehri P, Soleimani P, Fatahian R, Abdi A, Beiki O: Decompressive craniectomy in traumatic brain injury: Factors influencing prognosis and outcome. Iran J Neurosurg 3(1):21-26, 2017

3. Berz K, Divine J, Foss KB, Heyl R, Ford KR, Myer GD: Sexspecific differences in the severity of symptoms and recovery rate following sports-related concussion in young athletes. Phys Sportsmed 41(2):58-63, 2013

4. Bor-Seng-Shu E, Figueiredo EG, Amorim RL, Teixeira MJ, Valbuza JS, de Oliveira MM, Panerai RB: Decompressive craniectomy: A meta-analysis of influences on intracranial pressure and cerebral perfusion pressure in the treatment of traumatic brain injury. J Neurosurg 117:589-596, 2012

5. Bullock MR, Chesnut R, Ghajar J, Gordon D, Hartl R, Newell DW, Servadei F, Walters BC, Wilberger JE: Surgical management of acute subdural hematomas. Neurosurgery 58:S16-24, 2006 
6. Bullock MR, Chesnut R, Ghajar J, Gordon D, Hartl R, Newell DW, Servadei F, Walters BC, Wilberger J: Surgical management of traumatic parenchymal lesions. Neurosurgery 58:S25-46, 2006

7. Choi SC, Narayan RK, Anderson RL, Ward JD: Enhanced specificity of prognosis in severe head injury. J Neurosurg 69(3):381-385, 1988

8. Compagnone C, Murray GD, Teasdale GM, Maas Al, Esposito D, Princi P, D'Avella D, Servadei F: The management of patients with intradural posttraumatic mass lesions: A multicenter survey of current approaches to surgical management in 729 patients coordinated by the European Brain Injury Consortium. Neurosurgery 57:1183-1192, 2005

9. Cooper DJ, Rosenfeld JV, Murray L, Arabi YM, Davies AR, D'Urso P, Kossmann T, Ponsford J, Seppelt I, Reilly P, Wolfe R: Decompressive craniectomy in diffuse traumatic brain injury. N Engl J Med 364(16):1493-1502, 2011

10. De Cola MC, Corallo F, Pria D, Lo Buono V, Calabrò RS: Timing for cranioplasty to improve neurological outcome: A systematic review. Brain Behav 8(11):e01106, 2018

11. Demetriades D, Kuncir E, Velmahos GC, Rhee P, Alo K, Chan LS: Outcome and prognostic factors in head injuries with an admission Glasgow Coma Scale score of 3. Arch Surg 139(10):1066-1068, 2004

12. Erdogan E, Duz B, Kocaoglu M, Izci Y, Sirin S, Timurkaynak $E$ : The effect of cranioplasty on cerebral hemodynamics: Evaluation with transcranial Doppler sonography. Neurol India $51: 479-481,2003$

13. Fawley N, Udeh C: Sinking skin flap syndrome after decompressive craniectomy: A case report. A A Pract 11(9):241-243, 2018

14. Gillett GR, Honeybul S, Ho KM, Lind CR: Neurotrauma and the RUB: where tragedy meets ethics and science. J Med Ethics 36:727-730, 2010

15. Grille P, Tommasino N: Decompressive craniectomy in severe traumatic brain injury: Prognostic factors and complications. Rev Bras Ter Intensiva 27(2):113-118, 2015

16. Haddad SH, Arabi YM: Critical care management of severe traumatic brain injury in adults. Scand J Trauma Resusc Emerg Med 20:12, 2012

17. Honeybul S: Complications of decompressive craniectomy for head injury. J Clin Neurosci 17(4):430-435, 2010

18. Honeybul S, Ho KM, Lind CR, Gillett GR: Surgical intervention for severe head injury: ethical considerations when performing life-saving but non-restorative surgery. Acta Neurochir (Wien) 153:1105-1110, 2011

19. Hukkelhoven CW, Steyerberg EW, Rampen AJ, Farace E, Habbema JD, Marshall LF, Murray GD, Maas Al: Patient age and outcome following severe traumatic brain injury: An analysis of 5600 patients. J Neurosurg 99(4):666-673, 2003

20. Hutchinson PJ, Kolias AG, Timofeev IS, Corteen EA, Czosnyka M, Timothy J, Anderson I, Bulters DO, Belli A, Eynon CA, Wadley J, Mendelow AD, Mitchell PM, Wilson MH, Critchley G, Sahuquillo J, Unterberg A, Servadei F, Teasdale GM, Pickard JD, Menon DK, Murray GD, Kirkpatrick PJ, RESCUEicp Trial Collaborators: Trial of decompressive craniectomy for traumatic intracranial hypertension. New England Journal of Medicine 375(12):1119-1130, 2016
21. Jennett $B$, Bond M: Assessment of outcome after severe brain damage. Lancet 1(7905):480-484, 1975

22. Juul N, Morris GF, Marshall SB, Marshall LF: Intracranial hypertension and cerebral perfusion pressure: Influence on neurological deterioration and outcome in severe head injury. The Executive Committee of the International Selfotel Trial. J Neurosurg 92(1):1-6, 2000

23. Katsnelson M, Mackenzie L, Frangos S, Oddo M, Levine JM, Pukenas B, Faerber J, Dong C, Kofke WA, le Roux PD: Are initial radiographic and clinical scales associated with subsequent intracranial pressure and brain oxygen levels after severe traumatic brain injury? Neurosurgery 70(5):1095-1105, 2011

24. Kodliwadmath HB, Koppad SN, Desai M, Badiger SP: Correlation of Glasgow outcome score to Glasgow coma score assessed at admission. Int Surg J 3:1959-1963, 2016

25. Kolias AG, Adams H, Timofeev I, Czosnyka M, Corteen EA, Pickard JD, Turner C, Gregson BA, Kirkpatrick PJ, Murray GD, Menon DK, Hutchinson PJ: Decompressive craniectomy following traumatic brain injury: Developing the evidence base. Br J Neurosurg 30(2):246-250, 2016

26. Kolias AG, Kirkpatrick PJ, Hutchinson PJ: Decompressive craniectomy: Past, present and future. Nat Rev Neurol 9:405415, 2013

27. Kraus JF, Peek-Asa C, McArthur D: The independent effect of gender on outcomes following traumatic brain injury: $A$ preliminary investigation. Neurosurg Focus 8(1):e5, 2000

28. Kurland DB, Khaladj-Ghom A, Stokum JA, Carusillo B, Karimy JK, Gerzanich V, Sahuquillo J, Simard JM: Complications associated with decompressive craniectomy: A systematic review. Neurocrit Care 23(2):292-304, 2015

29. Lang JK, Ludwig HC, Mursch K, Zimmerer B, Markakis $\mathrm{E}$ : Elevated cerebral perfusion pressure and low colloid osmotic pressure as a risk factor for subdural spaceoccupying hygromas? Surg Neurol 52(6):630-637, 1999

30. Leitgeb J, Mauritz W, Brazinova A, Janciak I, Majdan M, Wilbacher I, Rusnak M: Outcome after severe brain trauma due to acute subdural hematoma. J Neurosurg 117(2):324333, 2012

31. Marshall LF, Marshall SB, Klauber MR, Van Berkum Clark M, Eisenberg H, Jane JA, Luerssen TG, Marmarou A, Foulkes MA: The diagnosis of head injury requires a classification based on computed axial tomography. J Neurotrauma 9(1): S287-292, 1992

32. Mezue WC, Ndubuisi CA: Decompressive craniectomy in the management of traumatic brain injury: A review of current practice. Open Access Surgery 8:73-83, 2015

33. Miller JD, Becker DP: Secondary insults to the injured brain. J R Coll Surg Edinb 27(5):292-298, 1982

34. Mohammadifard M, Ghaemi K, Hanif H, Sharifzadeh G, Haghparast M: Marshall and rotterdam computed tomography scores in predicting early deaths after brain trauma. Eur $\mathrm{J}$ Transl Myol 28(3):7542, 2018

35. Monsivais D, Choi HA, Kitagawa R, Franch M, Cai C: A retrospective analysis of surgical outcomes for acute subdural hematoma in an elderly cohort. Interdisciplinary Neurosurgery $14: 130-134,2018$ 
36. Moon JW, Hyun DK: Decompressive craniectomy in traumatic brain injury: A review article. Korean J Neurotrauma 13(1):1-8, 2017

37. Mushkudiani NA, Engel DC, Steyerberg EW, Butcher I, Lu J, Marmarou A, Slieker F, McHugh GS, Murray GD, Maas Al: Prognostic value of demographic characteristics in traumatic brain injury: Results from the IMPACT study. J Neurotrauma 24(2):259-269, 2007

38. Mutch CA, Talbott JF, Gean A: Imaging evaluation of acute traumatic brain injury. Neurosurg Clin N Am 27(4):409-439, 2016

39. Phan K, Moore JM, Griessenauer C, Dmytriw AA, Scherman DB, Sheik-Ali S, Adeeb N, Ogilvy CS, Thomas A, Rosenfeld JV: Craniotomy versus decompressive craniectomy for acute subdural hematoma: Systematic review and meta-analysis, World Neurosurgery 101:677-685, 2017

40. Renner C, Hummelsheim H, Kopczak A, Steube D, Schneider HJ, Schneider M, Kreitschmann-Andermahr I, Jordan M, Uhl E, Stalla GK: The influence of gender on the injury severity, course and outcome of traumatic brain injury. Brain Inj 26(11): 1360-1371, 2012

41. Rossini Z, Nicolosi F, Kolias AG, Hutchinson PJ, De Sanctis $\mathrm{P}$, Servadei $\mathrm{F}$ : The history of decompressive craniectomy in traumatic brain injury. Front Neurol 10:458, 2019

42. Sahuquillo J, Arikan F: Decompressive craniectomy for the treatment of refractory high intracranial pressure in traumatic brain injury. Cochrane Database Syst Rev 1:CD003983, 2006

43. Späni CB, Braun DJ, Van Eldik LJ: Sex-related responses after traumatic brain injury: Considerations for preclinical modeling. Front Neuroendocrinol 50:52-66, 2018

44. Stiver SI: Complications of decompressive craniectomy for traumatic brain injury. Neurosurg Focus 26(6):E7, 2009

45. Stulemeijer M, van der Werf SP, Jacobs B, Biert J, van Vugt AB, Brauer JM, Vos PE: Impact of additional extracranial injuries on outcome after mild traumatic brain injury. J Neurotrauma 23(10):1561-1569, 2006
46. Taylor A, Butt W, Rosenfeld J, Shann F, Ditchfield M, Lewis E, Klug G, Wallace D, Henning R, Tibballs J: A randomized trial of very early decompressive craniectomy in children with traumatic brain injury and sustained intracranial hypertension. Childs Nerv Syst 17:154-162, 2001

47. Teasdale G, Jennett B: Assessment of coma and impaired consciousness. A practical scale. Lancet 2(7872):81-84, 1974

48. Teasdale G, Jennett B: Assessment and prognosis of coma after head injury. Acta Neurochir (Wien) 34(1-4):45-55, 1976

49. van Leeuwen N, Lingsma HF, Perel P, Lecky F, Roozenbeek B, Lu J, Shakur H, Weir J, Steyerberg EW, Maas Al; International Mission on Prognosis and Clinical Trial Design in TBI Study Group; Corticosteroid Randomization After Significant Head Injury Trial Collaborators; Trauma Audit and Research Network: Prognostic value of major extracranial injury in traumatic brain injury: An individual patient data meta-analysis in 39,274 patients. Neurosurgery 70(4):811-818, 2012

50. Wen L, Wang H, Wang F, Gong JB, Li G, Huang X, Zhan RY, Yang XF: A prospective study of early versus late craniectomy after traumatic brain injury. Brain Inj 25:1318-1324, 2011

51. Wilberger JE Jr, Harris M, Diamond DL: Acute subdural hematoma: Morbidity, mortality, and operative timing. J Neurosurg 74(2):212-218, 1991

52. Woertgen C, Rothoerl RD, Schebesch KM, Albert R: Comparison of craniotomy and craniectomy in patients with acute subdural haematoma. J Clin Neurosci 13:718-721, 2006

53. Zhao HX, Liao Y, Xu D, Wang QP, Gan Q, You C, Yang $\mathrm{CH}$ : Prospective randomized evaluation of therapeutic decompressive craniectomy in severe traumatic brain injury with mass lesions (PRECIS): Study protocol for a controlled trial. BMC Neurol 5(16):1, 2016

54. Yang XF, Wen L, Shen F, Li G, Lou R, Liu WG, Zhan RY: Surgical complications secondary to decompressive craniectomy in patients with a head injury: A series of 108 consecutive cases. Acta Neurochir (Wien) 150(12):1241-1247, 2008 